\title{
Pengaruh Perawatan Metode Kanguru terhadap Respons Fisiologis Bayi Prematur
}

\section{The Influence of Kangaroo Mother Care on Physiological Response of Premature Infants}

\author{
Deswita* Besral** Yeni Rustina****
}

*Program Studi Ilmu Keperawatan Universitas Andalas, **Fakultas Kesehatan Masyarakat Universitas Indonesia, ***Fakultas Keperawatan Universitas Indonesia

\begin{abstract}
Abstrak
Saat ini, perawatan metode kanguru mulai dianjurkan bagi bayi prematur karena kelahiran prematur dan bayi dengan berat badan lahir rendah merupakan salah satu penyebab kematian bayi terbesar. Tujuan penelitian ini adalah untuk mengetahui pengaruh perawatan metode kanguru terhadap respons fisiologis bayi prematur. Desain quasi experiment one group pre and post-test dilakukan di 2 rumah sakit di Jakarta. Sebanyak 16 bayi prematur yang memenuhi kriteria inklusi dipilih sebagai sampel. Hasil penelitian menunjukkan bahwa terdapat pengaruh yang bermakna dari perawatan metode kanguru terhadap respons fisiologis bayi prematur seperti peningkatan suhu tubuh ke arah suhu nornal ( $p$ value $=0,000$ ), peningkatan frekuensi denyut jantung ke arah normal ( $p$ value $=0,003$ ), dan peningkatan saturasi oksigen ke arah normal ( $p$ value $=0,023$ ). Oleh karena itu, metode perawatan kanguru merupakan cara yang efektif, mudah, dan murah untuk merawat bayi prematur.
\end{abstract}

Kata kunci: Bayi prematur, perawatan metode kanguru, fisiologis bayi

\begin{abstract}
As premature birth and low birth weight are the main cause of neonatal mortality, kangaroo mother care is now suggested to care premature infants. The purpose of this study was to identify the effect of kangaroo mother care on physiological response of preterm infants. A quasi experiment design with one group pre and post test design was conducted in two hospitals in Jakarta. Sixteen preterm infants matching the inclusive criteria were selected as sample. The study found significant effect of kangaroo mother care intervention on physiological response of preterm infants, i.e. increasing body temperature to normal ( $p$ value $=0,000$ ), increasing heart rate to normal ( $p$ value $=0,003$ ), and increasing oxygen saturation ( $p$ value $=0,023$ ). Therefore, the kangaroo mother care is therefore an effective, simple, and cheap method to care the preterm infants.
\end{abstract}

Key words: Preterm infants, kangaroo mother care, physiological responses

\section{Pendahuluan}

Indonesia merupakan salah satu negara di Asia yang memiliki jumlah kematian bayi tertinggi. Laporan Survei Demografi Kesehatan Indonesia (SDKI) tahun 2007 menyebutkan angka kematian bayi di Indonesia adalah 34 per 1000 kelahiran hidup. ${ }^{1}$ Sulani, ${ }^{2}$ juga menyatakan bahwa setiap hari ada 240 bayi di Indonesia yang meninggal sebelum berumur 1 tahun dan diperkirakan setiap 1 jam ada 10 bayi meninggal atau setiap 6 menit ada 1 bayi baru lahir meninggal dunia.

Kelahiran prematur dan bayi dengan berat badan lahir rendah adalah penyebab terbesar angka kematian bayi diikuti kejadian infeksi. ${ }^{3}$ Hasil penelitian menyebutkan bahwa bayi prematur mempunyai kesulitan untuk beradaptasi dengan kehidupan ekstra uterin akibat ketidakmatangan sistem organ tubuhnya seperti paru-paru, jantung, ginjal, hati, dan sistem pencernaannya.

Bayi prematur secara umum belum mempunyai kematangan dalam sistem pertahanan tubuh untuk beradaptasi dengan lingkungan. Bayi prematur yang mempunyai berat lahir rendah cenderung mengalami hipotermi. Hal ini disebabkan karena tipisnya lemak subkutan pada bayi sehingga sangat mudah dipengaruhi oleh suhu lingkungan. Pada umumnya, bayi prematur dan mempunyai berat lahir rendah harus dirawat dalam inkubator. ${ }^{4}$

Perawatan bayi dalam inkubator menyebabkan adanya pemisahan ibu dengan bayi baru lahir. Kondisi ini merupakan salah satu penyebab timbulnya kurang per-

Alamat Korespondensi: Deswita, Program Studi Ilmu Keperawatan Universitas Andalas Jl. Niaga No. 156, Padang, Sumatera Barat Hp. 081363488349,

e-mail: deswitapsik@yahoo.com 
caya diri ibu dalam merawat bayinya. Ibu yang memiliki bayi prematur atau kurang bulan ditemukan kurang percaya diri dalam merawat bayinya dibandingkan dengan ibu yang memiliki bayi cukup bulan. ${ }^{5}$ Sebuah inovasi baru dalam perawatan bayi lahir prematur yang mendekatkan bayi dan ibunya adalah perawatan metode kanguru atau disingkat dengan PMK. ${ }^{4}$

Definisi perawatan metode kanguru (PMK) adalah suatu metode perawatan bayi baru lahir dengan meletakkan bayi diantara kedua payudara ibu sehingga terjadi kontak langsung kulit ibu dengan kulit bayi.4,6 Pengertian lain tentang PMK adalah cara merawat bayi dalam keadaan telanjang (hanya memakai popok dan topi), diletakkan secara tegak/vertikal tengkurap di dada antara kedua payudara ibunya (ibunya telanjang dada) kemudian diselimuti. Dengan demikian, terjadi kontak kulit bayi dan ibu secara kontinyu dan bayi memperoleh panas (sesuai suhu tubuh ibunya) melalui proses konduksi. 5,7

Perawatan metode kanguru dapat dilakukan dengan 2 cara. Pertama, secara terus-menerus dalam 24 jam atau yang disebut juga dengan secara kontinu dan kedua secara intermiten atau dengan cara selang-seling. PMK disarankan untuk dilakukan secara kontinu, akan tetapi rumah sakit yang tidak menyediakan fasilitas rawat gabung dapat menggunakan PMK secara intermiten. Pelaksanaan PMK secara intermiten juga memberikan manfaat sebagai pelengkap perawatan konvensional atau inkubator. $^{7}$

Tujuan penelitian ini adalah untuk mengetahui seberapa besar pengaruh perawatan metode kanguru terhadap fungsi fisiologis pada bayi lahir prematur. Variabel yang diukur terdiri dari suhu tubuh, frekuensi denyut jantung, dan saturasi oksigen.

\section{Metode}

Desain yang digunakan dalam penelitian ini adalah kuasi eksperimental dengan jenis one group pre-post-test design. 5,8 Penelitian dilakukan selama 3 bulan, April-Juni tahun 2010 di Ruang Perinatalogi Rumah Sakit Anak dan Bunda (RSAB) Harapan Kita dan Rumah Sakit Umum Pusat (RSUP) Fatmawati Jakarta.

Populasi penelitian ini adalah seluruh bayi prematur yang dirawat di Ruang Perinatalogi RSAB Harapan Kita dan RSUP Fatmawati di Jakarta. Sampel penelitian ini adalah bayi prematur stabil yang memenuhi kriteria inklusi berikut: 1) bayi berat lahir kurang dari 2500 gram, 2) suhu tubuh minimal $36^{\circ} \mathrm{C}$, dan 3) orang tua bayi memberikan persetujuan. Selain itu, bayi yang sudah masuk kriteria inklusi akan dikeluarkan dari studi dan dikembalikan ke dalam inkubator (kriteria eksklusi) jika terdapat tanda stres yang menetap termasuk takipnea, takikardi, ketidakstabilan suhu tubuh atau desaturasi oksigen. Dalam studi ini, metode sampling yang dipakai adalah total sampling artinya semua bayi dalam waktu 3 bulan penelitian yang memenuhi kriteria inklusi dipilih sebagai sampel. Selama 3 bulan tersebut didapat 16 sampel dengan rincian 10 sampel di RSUP Fatmawati dan 6 sampel di RSAB Harapan Kita.

Perawatan metode kanguru dilakukan selama 3 hari untuk setiap bayi. Pada hari pertama, diawali dengan pemberian penyuluhan kesehatan tentang PMK pada ibu bayi kemudian dilanjutkan dengan mengukur fungsi fisiologis bayi yang terdiri dari suhu tubuh, frekuensi denyut jantung, dan saturasi oksigen. Selain itu, kepada ibu bayi juga diberikan kuesioner untuk mengukur kepercayaan diri dalam merawat bayi kemudian si ibu melaksanakan metode PMK selama 1 jam. Pengukuran fungsi fisiologis segera dilakukan sesudah ibu melaksanakan PMK selama 1 jam. Pengukuran fungsi fisiologis bayi sebelum pelaksanaan PMK dilakukan sesaat sebelum bayi dilekatkan pada dada ibu, sedangkan pengukuran sesudah PMK dilakukan segera setelah bayi dalam posisi kanguru selama 1 jam.

Pada hari kedua, pengukuran fisiologis bayi dilakukan sebelum ibu melaksanakan PMK kemudian segera sesudah ibu melakukan PMK selama 1 jam dilakukan kembali pengukuran fungsi fisiologis bayi. Pada hari ketiga, pengukuran fungsi fisiologis bayi dilakukan sebelum dan sesudah PMK. Setelah itu, si ibu mengisi kuesioner untuk mengukur kepercayaan diri dan peneliti mengucapkan terima kasih atas partisipasi responden.

Analisis data dilakukan dengan bantuan program komputer yang mencakup analisis deskriptif untuk menghitung nilai rata-rata dan proporsi dari karakteristik ibu dan bayi serta analisis uji statistik (uji non-parametrik beda rata-rata data berpasangan atau Wilcoxon-test) untuk melihat pengaruh metode PMK terhadap fungsi fisiologis bayi. Uji Wilcoxon digunakan karena data tidak berdistribusi normal dan jumlah sampelnya sedikit. ${ }^{6}$

\section{Hasil}

Berdasarkan segi karakteristik bayi, bayi prematur jenis kelamin laki-laki lebih banyak (56\%) daripada perempuan (44\%). Rata-rata berat lahir sebesar 1.637,1 gram, sedangkan rata-rata umur bayi saat dilakukan penelitian yaitu 15 hari. Sedangkan, dari segi karakteristik ibu, rata-rata usia ibu adalah 34,9 tahun. Rata-rata masa gestasi adalah 32 minggu, sedangkan rata-rata paritas sebanyak 2 sampai 3 anak (Lihat Tabel 1).

Hasil analisis yang lebih detail memperlihatkan bahwa tidak terdapat perbedaan karakteristik bayi ataupun karakteristik ibu antara RSAB Harapan Kita dengan RSUP Fatmawati. Fungsi fisiologis bayi prematur sebelum dan sesudah PMK ditampilkan pada Tabel 2 sampai Tabel 5. Tabel 2 menunjukkan terdapat peningkatan suhu tubuh bayi ke arah normal setelah diberikan PMK. Pada hari pertama terjadi peningkatan suhu tubuh sebe- 
Tabel 1. Karakteristik Responden ( $\mathrm{n}=16)$

\begin{tabular}{lllcll}
\hline Variabel & Mean & Median & Standar Deviasi & Minimal & Maksimal \\
\hline Berat lahir (gram) & 1643,3 & 1600 & 235,6 & 1250 & 2000 \\
Umur bayi (hari) & 15,3 & 15,5 & 5,9 & 5 & 26 \\
Umur ibu (tahun) & 34,9 & 34,5 & 5,3 & 22 & 45 \\
Paritas & 2,6 & 3 & 0,9 & 1 & 4 \\
Gestasi (minggu) & 32,3 & 32 & 1,9 & 28 & 35 \\
\hline
\end{tabular}

Tabel 2. Rata-rata Suhu Tubuh Bayi Prematur Sebelum dan Sesudah PMK (n=16)

\begin{tabular}{ccccc}
\hline Suhu Tubuh $\left({ }^{\circ} \mathbf{C}\right)$ & Sebelum & Sesudah & Mean Selisih & Standar Deviasi \\
\hline Hari 1 & 36,6 & 36,8 & 0,23 & 0,18 \\
Hari 2 & 36,7 & 37,0 & 0,27 & 0,28 \\
Hari 3 & 36,7 & 37,0 & 0,30 & 0,17 \\
\hline
\end{tabular}

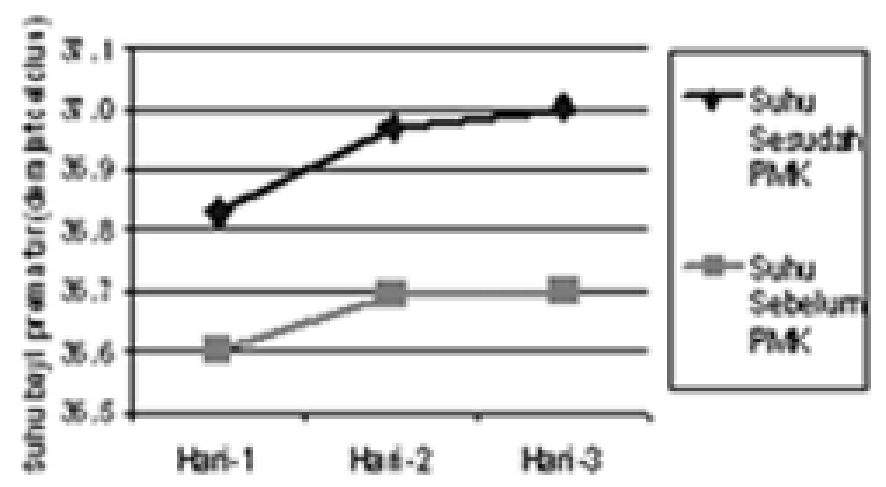

Gambar 1. Rata-rata Suhu Tubuh Bayi Prematur Sebelum dan Sesudah PMK (n=16)

sar $0,23^{\circ} \mathrm{C}$, hari kedua terjadi peningkatan sebesar $0,27^{\circ} \mathrm{C}$, sedangkan pada hari ketiga terjadi peningkatan suhu tubuh sebesar $0,3^{\circ} \mathrm{C}$ setelah diberikan PMK. Ketika dilakukan analisis yang lebih detail terlihat bahwa dari 16 responden semua bayi mengalami kenaikan denyut jantung ke arah normal sesudah pemberian PMK, tidak ada yang suhu tubuhnya tetap ataupun menurun setelah pemberian PMK.

Selain meningkatkan suhu tubuh ke arah normal, PMK juga berdampak terhadap peningkatan denyut jantung. Tabel 3 memperlihatkan bahwa terjadi kenaikan denyut jantung bayi prematur ke arah normal setelah pemberian PMK. Hari pertama, denyut jantung meningkat sebesar 2,88 kali per menit, hari kedua meningkat 2,00 kali per menit, dan hari ketiga meningkat sebesar 1,13 kali per menit. Ketika dilakukan analisis yang lebih detail terlihat bahwa dari 16 responden, sebanyak 10 bayi mengalami kenaikan denyut jantung ke arah normal sesudah pemberian PMK dan ada 6 bayi yang mengalami penurunan denyut jantung (data tidak ditampilkan). Bayi yang mengalami kenaikan denyut jantung, rata-rata denyut jantung sebelum PKM lebih rendah ( mean $=150$ kali per menit). Sedangkan, pada bayi yang mengalami penurunan denyut jantung, rata-rata denyut jantung bayi sebelum PMK lebih tinggi $($ mean $=156,6$ kali per menit).

Selain meningkatkan suhu tubuh ke arah normal dan peningkatan denyut jantung, PMK juga berdampak terhadap kenaikan saturasi oksigen. Tabel 4 memperlihatkan bahwa terdapat peningkatan saturasi oksigen sesudah pemberian PMK. Hari pertama terjadi peningkatan saturasi oksigen sebesar $0,56 \%$, hari kedua meningkat sebesar $0,44 \%$, sedangkan hari ketiga meningkat sebesar $0,50 \%$. Ketika dilakukan analisis yang lebih rinci terlihat bahwa dari 16 responden sebanyak 13 bayi mengalami peningkatan saturasi oksigen dan ada 3 
Tabel 3. Denyut Jantung Bayi Prematur Sebelum dan Sesudah PMK $(n=16)$

\begin{tabular}{ccccc}
\hline Denyut Jantung & Sebelum & Sesudah & Selisih & Standar Deviasi \\
\hline Hari 1 & 151,63 & 154,50 & 2,88 & 5,11 \\
Hari 2 & 153,19 & 155,19 & 2,00 & 4,03 \\
Hari 3 & 153,31 & 154,44 & 1,13 & 3,90 \\
\hline
\end{tabular}

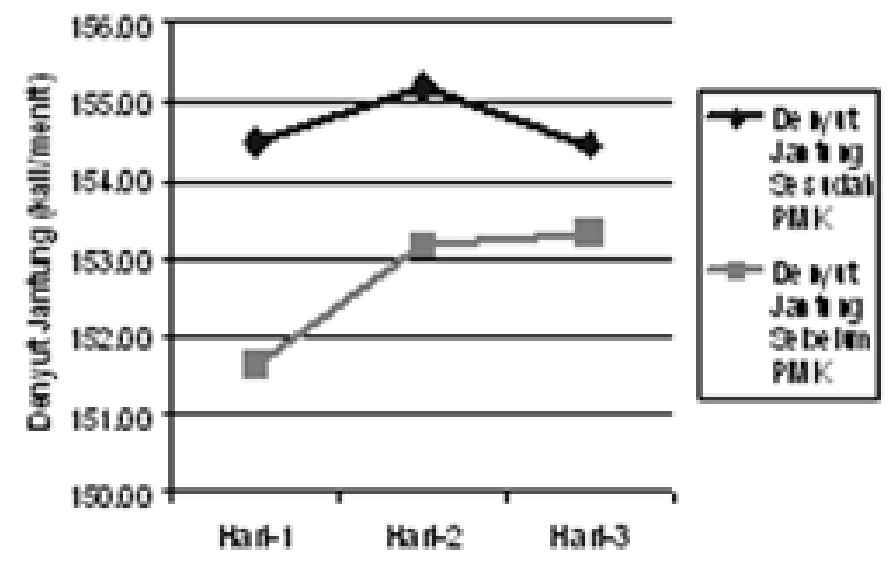

Gambar 2. Rata-rata Denyut Jantung Bayi Prematur Sebelum dan Sesudah PMK

Tabel 4. Saturasi Oksigen Bayi Prematur Sebelum dan Sesudah PMK (n=16)

\begin{tabular}{ccccc}
\hline Saturasi Oksigen $(\%)$ & Sebelum & Sesudah & Mean Selisih & Standar Deviasi \\
\hline Hari 1 & 95,5 & 96,1 & 0,56 & 1,26 \\
Hari 2 & 96,2 & 96,6 & 0,44 & 1,09 \\
Hari 3 & 96,1 & 96,6 & 0,50 & 2,00 \\
\hline
\end{tabular}

bayi yang mengalami penurunan saturasi oksigen sesudah dilakukan PMK. Bayi yang mengalami peningkatan saturasi oksigen, rata-rata saturasi oksigen sebelum PMK lebih rendah $($ mean $=93 \%)$. Sedangkan, bayi yang mengalami penurunan saturasi oksigen, rata-rata saturasi oksigen sebelum pemberian PMK lebih tinggi $($ mean = 97\%).

Dalam melihat pengaruh PMK terhadap fungsi fisiologis bayi dilakukan uji statistik dengan menggunakan uji Wilcoxon. Jenis uji ini dipilih karena data tidak berdistibusi normal dan sampelnya relatif sedikit hanya 16 responden. Fungsi fisiologis bayi yang diuji untuk melihat pengaruh dari metode PMK yaitu suhu tubuh, frekuensi denyut jantung, dan saturasi oksigen yang kemudian dibandingkan antara sebelum dan sesudah pemberian PMK.

Terlihat peningkatan respons fisiologis bayi prematur secara keseluruhan selama 3 hari antara sebelum dan sesudah PMK yaitu suhu tubuh bayi, denyut jantung, dan saturasi oksigen. Secara signifikan, PMK dapat menaikkan suhu tubuh bayi prematur ke arah suhu normal sebesar $0,27^{\circ} \mathrm{C}$ dengan nilai $\mathrm{p}=0,000$. PMK juga secara signifikan dapat meningkatkan denyut jantung ke arah normal sebesar 2,0 denyut per menit dengan nilai $\mathrm{p}$ $=0,002$. Sedangkan, saturasi $\mathrm{O}_{2}$ juga dapat ditingkatkan oleh PMK sebesar 0,5\% dengan nilai $\mathrm{p}=0,023$ (Lihat Tabel 5).

Pada suhu tubuh, semua responden bayi mengalami peningkatan suhu tubuh setelah pemberian PMK, sedangkan pada denyut jantung dan saturasi oksigen ada beberapa responden bayi yang mengalami penurunan. Penurunan respons fisiologis denyut jantung dan saturasi oksigen terjadi karena sebelum PMK respons fisiologisnya sudah tinggi, sedangkan pada kelompok yang meng- 


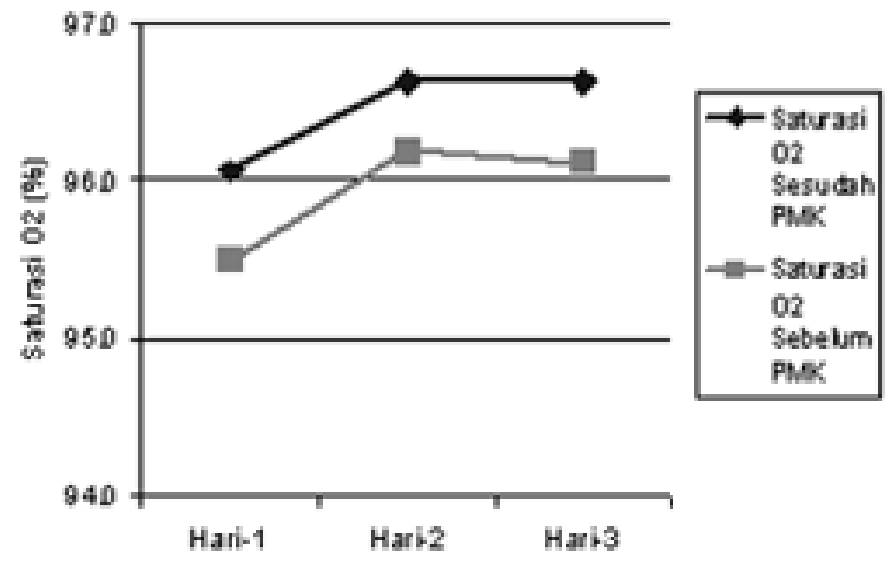

Gambar 2. Rata-rata Saturasi Oksigen Bayi Prematur Sebelum dan Sesudah PMK

Tabel 5. Suhu, Denyut Jantung, dan Saturasi Oksigen Bayi Prematur 3 Hari Sebelum dan Sesudah PMK Selama 3 Hari $(n=16)$

\begin{tabular}{lccccc}
\hline Saturasi Oksigen & Sebelum & Sesudah & Selisih & SD & Nilai p $^{*}$ \\
\hline Suhu tubuh $\left({ }^{\circ} \mathrm{C}\right)$ & 36,7 & 36,9 & 0,27 & 0,21 & 0,000 \\
$\begin{array}{l}\text { Denyut jantung } \\
\text { kali per menit) }\end{array}$ & 152,7 & 154,7 & 2,00 & 4,35 & 0,003 \\
Saturasi $\mathrm{O}_{2}(\%)$ & 95,9 & 96,4 & 0,50 & 1,47 & 0,023 \\
\hline
\end{tabular}

Keterangan: *Nilai p Uji Wilcoxon

alami peningkatan sebelum PMK respons fisiologisnya masih rendah. Dengan kata lain, PMK dapat menormalkan fungsi fisiologis bayi prematur apabila fungsi fisiologis terlalu tinggi maka PMK akan membuatnya menjadi turun (menuju ke arah normal), apabila fungsi fisiologis terlalu rendah maka PMK akan membuatnya menjadi naik (menuju ke arah normal).

\section{Pembahasan}

Hasil penelitian ini memperlihatkan bahwa PMK dapat meningkatkan secara bermakna suhu tubuh bayi ke arah normal. Hasil penelitian sejalan dengan penelitian yang dilakukan oleh Ali, ${ }^{9}$ pada 56 bayi prematur yang secara bermakna menunjukkan perbedaan suhu tubuh bayi antara kelompok kontrol dan kelompok intervensi dengan nilai $\mathrm{p}<0,001$. Hasil penelitian $\mathrm{Ali},{ }^{9}$ yang melakukan PMK selama 25 hari pada 114 bayi prematur menemukan bahwa suhu tubuh bayi yang dilakukan PMK mengalami peningkatan yang bermakna ke arah normal.

Pengaruh PMK terhadap peningkatan suhu tubuh bayi juga disampaikan oleh Ibe. ${ }^{10}$ Penelitiannya pada 13 bayi prematur yang diberikan PMK kemudian dilakukan observasi setiap 4 jam sesudah dilakukan PMK selama 38 jam dengan 7 kali memonitor suhu tubuh pada setiap responden. Hasil penelitiannya menunjukkan bahwa semua bayi yang dilakukan PMK mengalami kenaikan suhu tubuh yang bermakna dibandingkan bayi yang tidak dilakukan PMK. 10

Penelitian lain yang mendukung kenaikan suhu tubuh bayi prematur setelah dilakukan PMK dilaporkan oleh Begum, ${ }^{11}$ yang melakukan PMK selama 1 jam per hari pada 16 responden. Hasilnya, rata-rata kenaikan suhu tubuh sebesar $0,3^{\circ} \mathrm{C}$ dengan nilai $\mathrm{p}<0,01 .{ }^{11}$ Hasil penelitian ini juga sesuai dengan hasil penelitian lain bahwa ibu mampu mengontrol suhu tubuh bayi lebih baik daripada inkubator. Menurut Shetty, ${ }^{12}$ PMK dapat menyebabkan suhu tubuh dapat meningkat $2^{\circ} \mathrm{C}$ jika bayi kedinginan dan dapat menurunkan $1{ }^{\circ} \mathrm{C}$ jika bayi kepanasan.

Hasil penelitian ini juga sesuai dengan penelitian yang menyebutkan bahwa beberapa manfaat PMK adalah stabilisasi suhu tubuh, stabilisasi frekuensi denyut jantung, dan perilaku bayi yang lebih baik, misalnya tangisan bayi berkurang dan sewaktu bangun bayi terlihat lebih was- 
pada. $^{7}$

Terkait dengan denyut jantung, hasil penelitian ini memperlihatkan bahwa setelah dilakukan PMK terjadi kenaikan yang bermakna pada denyut jantung ke arah normal. Hasil ini sejalan dengan penelitian yang dilakukan oleh Dodd,13 pada 53 responden dengan melakukan PMK selama 1,5 jam per hari yang mendapatkan frekuensi denyut jantung mengalami kenaikan secara bermakna. Hasil penelitian ini juga sejalan dengan penelitian Priya, ${ }^{4}$ yang juga menyebutkan bahwa PMK bermanfaat untuk kestabilan frekuensi denyut jantung. Kestabilan frekuensi denyut jantung terlihat dari kenaikan frekuensi denyut jantung dan penurunan terjadinya bradikardi dengan nilai $\mathrm{p}=0,000$.

Hasil penelitian lain yang menggunakan pneumokardiogram dengan melakukan pengamatan pada frekuensi denyut jantung bayi menunjukkan bahwa pola respirasi dan frekuensi denyut jantung bayi selama perawatan metode kanguru lebih stabil dibanding perawatan dalam boks atau perawatan konvensional. ${ }^{7}$

Kajian teoritis memperlihatkan bahwa bayi prematur cenderung mengalami bradikardi. PMK akan mempunyai pengaruh positif pada bayi prematur yang bradikardi karena bayi merasakan detak jantung ibu sehingga bayi yang sedang bradikardi akan terstimulasi agar jantungnya kembali berdenyut mengiringi detak jantung si ibu. ${ }^{14}$

Hasil penelitian ini juga memperlihatkan bahwa PMK dapat meningkatkan secara bermakna saturasi oksigen ke arah normal. Hasil penelitian ini sejalan dengan penelitian yang dilakukan Priya, ${ }^{4}$ yang menyebutkan bahwa PMK dapat menaikkan level saturasi oksigen secara signifikan pada penelitian sebanyak 30 bayi yang mempunyai berat badan lahir rendah.

Selain itu, hasil penelitian Ali, ${ }^{9}$ juga melaporkan bahwa PMK dapat menjaga kestabilan saturasi oksigen. PMK secara bermakna dapat mengurangi frekuensi nafas dan meningkatkan saturasi oksigen. Hal ini dapat disebabkan oleh posisi bayi yang tegak sehingga gravitasi bumi mempunyai dampak positif dan berefek pada ventilasi dan perfusi. Posisi tegak pada bayi dapat mengoptimalkan fungsi respirasi. ${ }^{9}$

Menurut peneliti, saturasi oksigen cenderung mengalami penurunan apabila frekuensi denyut jantung mengalami bradikardi atau takikardi. Frekuensi denyut jantung yang sangat lambat atau sangat cepat akan mempengaruhi sirkulasi darah ke seluruh tubuh. Sirkulasi darah yang tidak adekuat ke seluruh tubuh terutama bagian perifer dapat menurunkan oksigen dalam darah bagian perifer sehingga saturasi oksigen yang dipantau melalui pulseoxymetri menunjukkan kurang dari $90 \%$.

Beberapa hasil penelitian masih ada yang kontroversial dimana dilaporkan bahwa tidak ada pengaruh bermakna PMK terhadap saturasi oksigen pada bayi pre- matur. Salah satu penelitian yang melakukan PMK pada 20 responden memperlihatkan bahwa tidak ada kenaikan bermakna pada saturasi oksigen sesudah 2 jam dilakukan PMK. ${ }^{13}$ Selain itu, hasil penelitian lain yang menyebutkan bahwa tidak ada perbedaan saturasi oksigen sebelum dan sesudah PMK pada bayi dengan berat badan lahir rendah dilaporkan oleh Mooncey dalam Dodds, ${ }^{13}$ yang melakukan PMK pada 15 bayi dengan berat badan lahir kurang dari 1.800 gram. Perbedaan hasil ini mungkin dapat disebabkan oleh perbedaan karakteristik bayi. Mooncey dalam Dodds, ${ }^{13}$ menggunakan bayi yang berat lahirnya kurang dari 1.800 gram, sedangkan pada penelitian ini berat bayi berkisar antara 1.250 sampai 2.000 gram.

Penelitian ini telah membuktikan bahwa PMK dapat meningkatkan suhu tubuh, frekuensi denyut jantung, dan saturasi oksigen pada bayi prematur ke arah normal. Penulis berkesimpulan bahwa PMK dapat diimplementasikan dalam penerapan asuhan keperawatan pada bayi neonatus,terutama dalam kondisi keterbatasan penyediaan inkubator bagi bayi prematur. Walaupun PMK sebaiknya dilakukan oleh ibu dari si bayi, namun dalam keterbatasan waktu karena ibu bekerja, PMK dapat dilakukan oleh ibu mana pun termasuk oleh petugas kesehatan dengan syarat baik ibu si bayi maupun petugas kesehatan yang akan memberikan PMK terlebih dahulu harus mendapatkan pendidikan kesehatan dan pelatihan terkait PMK.

Peneliti juga menyarankan agar ruang perinatologi sebaiknya memiliki ruangan khusus PMK dan pihak rumah sakit menyediakan rumah singgah bagi ibu agar dapat mengunjungi bayinya setiap hari sehingga dapat memberikan PMK. Selain itu, perawat diharapkan dapat memberikan inhouse training bagi ibu yang memiliki bayi prematur agar PMK dapat dilakukan di rumah setelah bayi pulang dari rumah sakit.

Penelitian ini dapat dijadikan dasar bagi penelitian lanjutan yang berhubungan dengan PMK dan fungsi fisiologis bayi. Diharapkan penelitian lanjutan dengan jumlah sampel yang lebih besar agar dapat melihat lebih rinci pengaruh dari variabel lain dalam meningkatkan fungsi fisiologis bayi prematur, seperti jenis kelamin, umur, dan berat badan yang dalam penelitian ini belum dilihat karena sampelnya sangat kecil. Berdasarkan adanya keterbatasan penelitian ini yang terkait dengan prosedur penelitian dapat dilakukan penelitian lain dengan prosedur yang lebih ketat, yaitu melakukan pemantauan pada fisiologis secara lebih lengkap, tidak hanya sebelum dan sesudah PMK, tetapi juga selama diberikan PMK.

\section{Kesimpulan}

Sebagian besar berjenis kelamin laki laki $(56,2 \%)$, rata-rata berumur 15,4 hari, dan rata-rata berat badan lahir adalah 1.637,1 gram dengan berat tertinggi 2.000 gram. 
Rata-rata usia ibu adalah 34,9 tahun, dan rata-rata masa gestasi 32,4 bulan. Bayi prematur dan berat lahir rendah ditemukan pengaruh PMK yang bermakna terhadap peningkatan suhu tubuh, frekuensi denyut jantung, dan saturasi oksigen ke arah normal.

\section{Saran}

Perawatan metode kanguru yang selama ini dilakukan di Ruang Perinatalogi RSAB Harapan Kita dan RSUP Fatmawati dapat dijadikan tindakan rutin dan dijadikan kebijakan oleh pihak rumah sakit. Ruang perinatalogi sebaiknya memiliki ruangan khusus PMK dan pihak rumah sakit menyediakan rumah singgah bagi ibu agar dapat mengunjungi bayinya setiap hari untuk memberikan PMK.

\section{Daftar Pustaka}

1. Statistics Indonesia and Macro International. Indonesia demographic and health survey 2007. Calverton, Maryland, USA: Statistics Indonesia and Macro International; 2008.

2. Sulani F. Masalah pertumbuhan janin terhambat (PJT) dan bayi berat lahir rendah (BBLR) di Indonesia dalam Kongres Nasional X Perinasia. Banjarmasin; 2009.

3. Sloan NL. Community based kangaroo mother care to prevent neonatal and infant mortality: a randomized controlled cluster trial. Pediatrics. 2008 [cited 2009 November 20]; 121 (5): e1047e1059. Available from: http://www.pediatrics.org.

4. Priya JJ. Kangaroo care for low birth weight babies. Nursing Journal of India. 2004 [cited 2009 November 20); (95) 9: 209-212. Available from: http://www.proquest.umi.com.

5. Williams. Transition to motherhood: a longitudinal study. Infant Mental
Health Journal. 1987 [cited 2010 January 20]; 8 (4): 251-265 dalam Doxtator LA. (2003). Maternal confidence acomparison between mothers of term and preterm infants by feeding method [tesis]. Canada: Queen's University. Available from: http://www.proquest.umi.com.

6. Arora S. Kangaroo mother care. Nursing Journal of India. 2008 [cited 2009 November 20]; 99 (11): 248-250. Available from: http://www.proquest.umi.com.

7. Perinasia. Perawatan bayi berat lahir rendah dengan perawatan metode kanguru. Jakarta: Perinasia; 2003.

8. Sastroasmoro S, Ismael S. Dasar-dasar metodologi penelitian klinis. Jakarta: Sagung Seto; 2008.

9. Ali SM, Sharma J, Sharma R, Alam S. Kangaroo mother care as compared to conventional care for low birth weight babies. DicleTipDerg/Dicle Med J. 2009 [cited 2009 November 20]; 36 (3): 155-160. Available from: http://www.proquest.umi.com.

10. Ibe OE, Austin T, Sulliva K, Fabanwo O, Disu E, Costello AMDL. A comparison of kangaroo mother care and conventional incubator care for thermal regulation of infants $<2000$ gr in Nigeria using continuous ambulatory temperatire monitoring. Annals of Tropical Paediatrics. 2004 [cited 2010 January 20]; 24: 245-251. Available from: http://www.proquest.umi.com.

11. Begum EA. Cerebral oxygenation responses during kangaroo care in low birth weight infants. BCM Pediatrics. 2008 [cited 2009 November 30]; 8 (51): 19. Available from: http://www.biomedcentral.com.

12. Shetty AP. Kangaroo mother care. Nursing Journal of India. 2007 [cited 2009 November 20]; 98 (11): 249-250. Available from: http://www.proquest.umi.com.

13. Dodd VL. Effects kangaroo care in preterm infants. 2003 [cited 2010 February 4]. Available from: http://www.proquest.umi.com.

14. Bobak IM, Lowdermik DL, Jensen MD. Keperawatan maternitas. 4th ed. Jakarta: Penerbit EGC; 2005. 